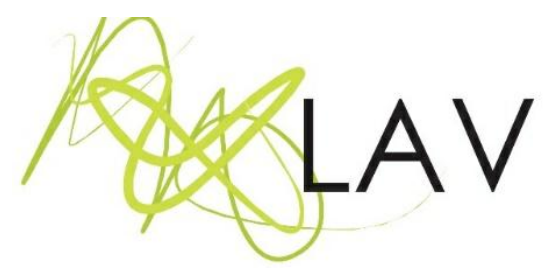

\title{
As TIC no desenho curricular do Curso de Licenciatura em Artes Visuais do IFMA
}

\author{
ICT in the curriculum design of the visual arts degree course at IFMA
}

William Cordeiro Costa

Instituto Federal do Maranhão

Luciana Silva Aguiar Mendes Barrosii

Instituto Federal do Maranhão

\begin{abstract}
Resumo
As Tecnologias da Informação e Comunicação (TIC) encontram-se integradas de forma marcante na vida da sociedade contemporânea e seu impacto nos processos educacionais tem motivado vários estudos, tendo em vista a importância da reflexão sobre a relação entre as tecnologias, currículo e formação docente. Seguindo essa demanda, este estudo tem como objetivo principal investigar as tecnologias no Curso de Licenciatura em Artes Visuais do IFMA, visando identificar como é a abordagem de tal temática a partir do desenho curricular do Curso. Os resultados obtidos indicam que as tecnologias são abordadas em determinadas disciplinas como instrumentos de produção artística contemporânea e em outras como ferramentas de mediação pedagógica. A partir de uma metodologia qualitativa, realizou-se um mapeamento do projeto pedagógico do curso, à luz dos documentos e dispositivos legais que regem o Curso de Licenciatura em Artes Visuais no Brasil, fundamentando a discussão a partir das concepções de teóricos, como Lévy (1993), Pimentel (2011), entre outros.
\end{abstract}

Palavras-chave: formação docente, artes visuais, tecnologias.

\begin{abstract}
Information and Communication Technologies (ICTs) are strongly integrated in the life of contemporary society and their impact on educational processes has motivated several studies, in view of the importance of reflecting on the relationship between technologies, curriculum and teacher training. Following this demand, this study has as main objective to investigate the technologies in the Visual Arts Degree Course at Instituto de Educação, Ciência e Tecnologia do Maranhão (IFMA), aiming at identifying the approach of this theme based on the curricular design of the Course. The results obtained indicate that the technologies are approached in certain disciplines as instruments of contemporary artistic production, and, in others, as tools of pedagogical mediation. The methodology adopted consisted of mapping the pedagogical project of the course, in light of the documents and legal provisions that conduct the Degree in Visual Arts in Brazil, supporting the discussion with basis on conceptions of theorists such as Lévy (1993), Pimentel (2011), among others.
\end{abstract}

Keywords: teacher training, visual arts, technologies. 


\section{Introdução}

De um lado, acompanhamos as tecnologias digitais em aceleradas mudanças e atualizações, do outro uma sociedade que tenta acompanhar e incorporar as novidades trazidas por elas no século XXI. Ainda no século passado, Lévy (1993) menciona que a humanidade vivenciou momentos importantes de transformações dos paradigmas das relações sociais, visto que uma civilização pautada na linguagem escrita passou a dar lugar a uma civilização baseada na informática. Já para Castells (2016), as revoluções industriais da Era Informacional reconfiguraram a sociedade contemporânea em uma sociedade em rede, a partir do surgimento de tecnologias cada vez mais elaboradas.

A aplicação das Tecnologias da Informação e Comunicação (TIC) ${ }^{1}$ no contexto escolar não é mais novidade diante de uma humanidade tão conectada pelos aparatos tecnológicos. Esse fato exige que os profissionais que atuam na educação necessitem de formação não só para lidar com as tecnologias disponíveis para suas aulas, mas também para utilizá-las em seus processos formativos.

A educação vem, ao longo dos anos, tentando acompanhar essas mudanças da sociedade do conhecimento. O uso das TIC na prática docente, nos cursos de formação inicial e continuada vem ganhando relevância devido a essas transformações. No entanto, para Kenski (2012, p. 94), o avanço tecnológico não foi articulado com as mudanças estruturais no processo de ensino, nas propostas curriculares e na formação dos professores universitários para a nova realidade educacional. Em muitos casos, as instituições de ensino superior iniciaram programas de capacitação para o uso dos novos equipamentos, mas as práticas pedagógicas permaneceram as mesmas ou retrocederam.

E, em muitos dos currículos de cursos de formação inicial de professores, há o predomínio de conteúdos desconexos e fragmentados, longe da nova realidade estabelecida na sociedade, os quais se tornam insuficientes para os desafios atuais. Segundo Imbernón (2001), historicamente nos estabelecimentos de formação docente predominam o ensino de conteúdos descontextualizados com a realidade, que não oferecem preparo suficiente para se aplicar uma nova metodologia, nem para aplicar métodos desenvolvidos teoricamente na prática de sala de aula. Destaca-se a importância de refletir a respeito da educação em Arte diante de tais discussões.

\footnotetext{
${ }^{1}$ Ao longo do texto se usará a sigla TIC para se referir às Tecnologias de Informação e Comunicação. Compreendese por Tecnologias de Informação e Comunicação os meios mais tradicionais, como rádio, televisão, equipamentos de áudio e vídeo, e meios eletrônicos como sistemas multimídias, softwares, internet, entre outros.
} 
No ensino de Arte, a cada novo avanço tecnológico, o educador ganha uma possibilidade de apropriação e ressignificação desses instrumentos, à medida que tais tecnologias favorecem novas formas de acesso ao conhecimento e à diversidade de saberes, auxiliando os professores no desenvolvimento de suas atividades e práticas pedagógicas. Porém, apenas a utilização da tecnologia não garante o desenvolvimento de um pensamento artístico ou da construção do conhecimento em Arte. Para Pimentel (2012), conhecer o instrumento de trabalho e as possibilidades que ele oferece é essencial, mas ir além da mera aplicação dessas possibilidades é imprescindível.

Desse modo, torna-se necessário que a academia propicie aos seus egressos conhecimentos conectados com as exigências educacionais do momento, vislumbrando desenvolver e implementar competências condizentes com o futuro profissional da educação. Nesse sentido, questiona-se como o currículo do Curso de Licenciatura em Artes Visuais do Instituto de Educação, Ciência e Tecnologia do Maranhão aborda a temática das TIC, e como se dá tal abordagem.

Tendo em vista a necessidade de refletir sobre as tecnologias, currículo e formação docente em artes visuais, este estudo tem como objetivo principal promover discussões a respeito do uso de tecnologias na formação inicial do licenciado(a) em Artes Visuais, a partir do mapeamento do desenho curricular do curso de formação, e identificar quais as disciplinas ofertadas no curso de Graduação exploram tal temática.

Diante disso, tal estudo pretende fazer um mapeamento documental, por meio do projeto pedagógico do curso e das ementas das disciplinas ofertadas na Licenciatura em Artes Visuais do Instituto de Educação, Ciência e Tecnologia do Maranhão (IFMA)², considerando a legislação brasileira concernente ao tema.

A fim de responder à questão norteadora deste estudo, o artigo organiza-se em três partes principais. Na primeira, fundamenta-se as discussões sobre a formação docente e os desafios contemporâneos da educação. Na segunda parte, aborda-se as relações entre as TIC e o ensino de Artes Visuais, apresentando documentos bases do ensino de Arte no Brasil, e os dispositivos que regem a Licenciatura em Artes Visuais. Por fim, na última parte, analisa-se o desenho curricular do referido curso.

\footnotetext{
${ }^{2}$ Ao longo deste artigo, utiliza-se a sigla IFMA para se referir ao Instituto de Educação, Ciência e Tecnologia do Maranhão.
} 


\section{A formação profissional docente no contexto da contemporaneidade}

A formação profissional docente é uma discussão permanente que tem sido tema de várias pesquisas no meio acadêmico nas últimas décadas, possibilitando o surgimento de inúmeros estudos nos últimos 20 anos. Nesse sentido, mais do que nunca se faz necessário a inclusão das TIC nos processos educativos de formação docente.

A formação inicial precisa dotar o profissional de educação de instrumentos intelectuais que sejam úteis em sua atuação como professor na educação básica. Essa etapa é muito importante, pois deve oferecer o preparo suficiente para a aplicação dos conhecimentos teóricos na prática de sala de aula (IMBERNÓN, 2006). Desse modo, o professor precisa reconstruir a maneira como mediar o conteúdo, a fim de inserir as TIC com a finalidade de auxiliar os processos de ensino e aprendizagem, considerando as realidades no qual está inserido.

A escola não pode ignorar o que se passa no mundo. Ora, as novas tecnologias de informação e comunicação (TIC ou NTIC) transformam espetacularmente não só nossas maneiras de comunicar, mas também de trabalhar, de decidir, de pensar. Formar para as novas tecnologias é formar o julgamento, o senso crítico, o pensamento hipotético e dedutivo (PERRENOUD, 2000, p. 123).

Portanto, reitera-se que importância de uma formação inicial (e permanente) no qual o professor desenvolva e implemente inovações em suas atividades profissionais. A ênfase na instrumentalização docente constitui-se como um dos eixos do marco político dos "Padrões de Competência em TIC para Professores", propostos pela UNESCO em 2009, elaborados com o objetivo de nortear discussões e fomentar debates sobre a formação de professores em todo o planeta, para o uso de novas tecnologias em sala de aula.

O documento apresenta diretrizes específicas para o planejamento de programas educacionais e para o aprimoramento do papel do professor como agente formador. Além disso, destaca que tanto os programas de desenvolvimento de profissionais na ativa, quanto os programas de preparação dos futuros docentes devem oferecer experiências adequadas em tecnologia, pois são eles os responsáveis em estabelecer o ambiente e preparar as oportunidades de aprendizagem que facilitem o uso das tecnologias.

As novas tecnologias demandam novos papéis para o professor, novas pedagogias e novas técnicas para o treinamento do docente. A adequada integração das TIC em sala de aula dependerá da habilidade dos professores em estruturar 0 ambiente de aprendizagem de modo não tradicional; em fundir a nova tecnologia com a nova pedagogia [...] As principais capacidades do futuro incluirão a capacidade de desenvolver formas inovadoras de usar a tecnologia para melhorar o ambiente de aprendizagem e incentivar

Revista Digital do LAV - Santa Maria - vol. 14, n. 1, p. 159 - 176 - jan./abr. 2021 ISSN 1983 - 7348 
a alfabetização em tecnologia, o aprofundamento do conhecimento e a criação do conhecimento (UNESCO, 2009, p. 9).

O Projeto da UNESCO de Padrões de Competência em TIC para Professores representa uma articulação para o planejamento de ações que visem a formação de professores, especificamente quanto ao uso de tecnologias para um desenvolvimento profissional adequado às novas demandas educacionais.

É recorrente afirmar que as instituições escolares e seu corpo docente ainda não estão preparados para receber esses novos estudantes, conectados com os recursos tecnológicos tão presentes em seu cotidiano desde a infância nos grandes centros urbanos. O fato é que a escola e seus professores precisam se posicionar diante da multiplicidade desses meios tecnológicos, entendendo o impacto deles no espaço escolar e em sua prática educativa.

Hoje a escola, os docentes e os alunos precisam se adaptar ao desafio de inserir diferentes tecnologias no processo de ensino e aprendizagem. A prática do docente em exercício não deve fugir dessa realidade; ao mesmo tempo em que precisa dominar conhecimentos e conceitos relacionados a determinado campo de conhecimento, precisa também ter afinidade com o aparato tecnológico.

Os(as) alunos(as) por pertencerem a uma geração que possui um contato maior com as tecnologias em seu dia a dia, parecem estar mais desenvoltos ao manusear os equipamentos eletrônicos, enquanto parte dos(as) professores(as) ainda podem possuir alguma dificuldade. Para encarar a situação como um novo aprendizado, é preciso um investimento em novos conhecimentos, o que pode provocar resistência em alguns. Nesse sentido, Imbernón (2001) comenta que a formação profissional deve dotar os professores de conhecimentos, habilidades e atitudes para desenvolver profissionais reflexivos e investigadores. Além disso, os futuros professores(as) devem estar preparados para atender às transformações inerentes à sociedade atual, adequando-se às necessidades do alunado em cada época e contexto vigente.

Nas universidades, grande parte do acesso aos conteúdos das aulas se dá por meio do computador ou de outros meios tecnológicos, fazendo com que os acadêmicos tenham contato direto com esses recursos e vivenciem sua aplicação nos processos de ensino e aprendizagem desde o início da carreira profissional. Por outro lado, ao se deparar com a realidade de seus ambientes de trabalho, nem sempre há condições de pôr em prática os conhecimentos adquiridos durante a sua formação. Isso ocorre devido a problemas na estrutura física das escolas, à falta de acesso à internet de qualidade, e ainda à falta de equipamentos adequados para o número de estudantes de cada turma. 
A partir disso, alguns estudos realizados tentam articular o uso pedagógico das tecnologias e os conteúdos abordados pelos currículos dos cursos de licenciaturas. Para Gatti e Barretto (2009), a maioria dos cursos superiores de formação de professores apresenta um rol de disciplinas fragmentadas, com um número pequeno de componentes curriculares voltados às tecnologias. Nesse sentido, faz-se necessário que as universidades repensem a estrutura e a organização das práticas de ensino nos cursos de formação docente.

Os formadores de professores, ou seja, os docentes de cursos de licenciaturas, também devem ser treinados para aplicar a tecnologia à aprendizagem, na apresentação e na condução de seus cursos e facilitar, assim, o uso adequado da tecnologia pelos alunos, futuros professores. Desde o primeiro ano, por intermédio do trabalho em equipe realizado nas instalações da instituição, os futuros professores devem ser incentivados a participar de atividades que Ihes permitam observar como seus tutores utilizam a tecnologia de forma eficaz (PÚBLIO JÚNIOR, 2018, p. 1092-1105).

O autor ainda defende que os ganhos educacionais relacionados ao aperfeiçoamento pedagógico que as tecnologias oportunizam abrangem o ensino individualizado, a autonomia do aluno, a mobilidade do conhecimento e as facilidades e inovações no ambiente escolar. Isto é, as tecnologias permitem romper com os modelos reprodutivos de conceitos amarrados e consolidados, incentivando o professor a inovar em suas práticas pedagógicas. Diante disso, os cursos de licenciatura precisam assumir a responsabilidade de oferecer aos alunos uma formação que transcenda uma perspectiva instrumental e desenvolva conhecimentos contextualizados às novas dinâmicas de ensino e aprendizagem.

Sabendo que as discussões que envolvem a utilização de tecnologias nos projetos pedagógicos dos cursos de formação inicial podem instrumentar os futuros docentes a inserirem o aparato tecnológico em suas atividades docentes para melhorar o processo de ensino e aprendizagem, os cursos de formação docente são desafiados a revisarem os seus currículos para acompanharem as necessidades atuais. É importante incluir esses novos conhecimentos como componentes básicos para a formação desse profissional que atuará na educação básica. Espera-se ainda que as instituições que promovem a formação de professores(as) se responsabilizem pela elaboração de uma estrutura curricular que prepare os profissionais para as demandas atuais da educação contemporânea e de acordo com a legislação vigente. E essa questão nos instiga a refletir a respeito de como a docência em artes visuais se relaciona com as tecnologias de informação e comunicação. 


\section{As TIC e a Docência em Artes Visuais}

A docência em Artes Visuais, assim como também de outras linguagens artísticas, vem passando por diversas mudanças ao longo dos anos, dentre outros motivos, temos o constante diálogo da arte com os diferentes artefatos tecnológicos. Desse modo, partimos do que diz o artista Kandinsky (1996) ao destacar que "toda obra de arte é filha de seu tempo [...]. Cada época de uma civilização cria uma arte que the é própria que jamais se verá renascer" (KANDINSKY, 1996, p. 27).

Existem diferentes maneiras de se lidar com as máquinas semióticas crescentemente disponíveis no mercado da eletrônica. A perspectiva artística é certamente a mais desviante de todas, uma vez que ela se afasta em tal intensidade do projeto tecnológico originalmente imprimido às máquinas e programas que equivale a uma completa reinvenção dos meios [...] Talvez até se possa dizer que um dos papéis mais importantes da arte numa sociedade tecnocrática seja justamente a recusa sistemática de submeter-se à lógica dos instrumentos de trabalho, ou de cumprir o projeto industrial das máquinas semióticas, reinventando, em contrapartida, as suas funções e finalidades (MACHADO, 2002, p. 23).

Seguindo tal pensamento, a arte acompanha as mudanças de sua época, assumindo formas e características particulares que são, em certo modo, demandadas do momento histórico, assim como se utiliza de materiais e técnicas disponíveis na sociedade na qual se insere. $\mathrm{O}(\mathrm{a})$ artista, por sua vez, possui o desafio de apropriar-se dos instrumentos à sua disposição de forma criativa e inovadora, a favor de suas concepções estéticas. Consequentemente, o ensino de Arte pode ser influenciado por tais mudanças, exigindo que os(as) professores(as) repensem suas práticas docentes no que tange ao uso dos instrumentos tecnológicos.

Diante desse contexto, os cursos de formação de professores de artes visuais devem ou deveriam abordar diferentes níveis de conhecimentos e competências necessárias para que o futuro docente possa aplicar em sua prática artística/pedagógica. Pimentel (2011) afirma que fica a cargo da formação do professor de Arte a responsabilidade de colaborar na tarefa de transformar o conjunto de conhecimentos e experiências em algo que possa ser aprendido, para que esses docentes sejam capazes de criar, produzir, pesquisar, teorizar, educar, provocar, refletir, construir trajetórias e aceitar desvios.

Seguindo esse pensamento, a docência em artes visuais precisa estabelecer conexões com os saberes adquiridos pelo estudante durante sua passagem no curso de graduação e as habilidades desenvolvidas em sua atuação docente para que o ensino de Arte cumpra seu papel no desenvolvimento intelectual humano. 
O ensino de Arte tem sua relevância e possui suas especificidades e desafios, assim como outras áreas. A Base Nacional Comum Curricular (BNCC) no que se refere ao ensino de Arte evidencia sua importância como campo do saber humano que favorece o desenvolvimento da imaginação e da percepção do mundo, possibilitando a autonomia por meio da reflexão, criatividade e expressão dos estudantes.

A Arte, enquanto área do conhecimento humano, contribui para o
desenvolvimento da autonomia reflexiva, criativa e expressiva dos
estudantes, por meio da conexão entre o pensamento, a
sensibilidade, a intuição e a ludicidade. Ela é, também, propulsora
da ampliação do conhecimento do sujeito sobre si, o outro e o
mundo compartilhado. É na aprendizagem, na pesquisa e no fazer
artístico que as percepções e compreensões do mundo se ampliam
e se interconectam, em uma perspectiva crítica, sensível e poética
em relação à vida, que permite aos sujeitos estar abertos às
percepços e experiências, mediante a capacidade de imaginar e
ressignificar os cotidianos e rotinas (BRASIL, 2017, p. 482).

$\mathrm{A} \mathrm{BNCC}^{3}$, documento de referência para elaboração dos currículos escolares e para propostas pedagógicas para a educação básica, propõe que a abordagem das linguagens artísticas articule dimensões de conhecimento, a fim de facilitar o processo de ensino e aprendizagem em Arte, integrando os conhecimentos do componente curricular. No documento voltado ao Ensino Fundamental, há uma última unidade chamada de artes integradas que explora as relações e articulações entre as diferentes linguagens (artes visuais, dança, música e teatro) e suas práticas, inclusive possibilidades de uso das tecnologias de informação e comunicação. Assim, a BNCC enfatiza que se deve "explorar diferentes tecnologias e recursos digitais (multimeios, animações, jogos eletrônicos, gravações em áudio e vídeo, fotografia, softwares etc.) nos processos de criação artística" (BRASIL, 2017, p. 203). Nas competências específicas do componente curricular para o ensino fundamental, encontra-se as seguintes orientações: "[m]obilizar recursos tecnológicos como formas de registro, pesquisa e criação artística" (Ibid., p. 198) e "[i]dentificar e manipular diferentes tecnologias e recursos digitais para acessar, apreciar, produzir, registrar e compartilhar práticas e repertórios artísticos, de modo reflexivo, ético e responsável" (BRASIL, 2017, p. 211).

Para isso, educadores em Arte precisam possibilitar o acesso aos estudantes às várias produções artísticas, apropriando-se de várias metodologias e inovações nos procedimentos educativos, para torná-lo mais acessível, fazendo com que se valorize as diversas produções como fontes de informações visuais, sonoras, corporais e verbais.

\footnotetext{
${ }^{3}$ A comissão responsável pela elaboração da BNCC cogitou retirar o componente curricular Arte da educação básica. Após várias manifestações, principalmente estudantis, por todo o Brasil, a disciplina foi mantida no texto final do documento.
} 
Dessa forma, é necessário proporcionar novas formas de acessar, pensar e fazer Arte. Surgem os desafios para o professor de Arte, pois precisa dominar conhecimentos e conceitos relacionados a arte, além de ter afinidade com o aparato tecnológico.

Diante dessa realidade, a cada novo instrumento tecnológico, o educador em Arte ganha uma possibilidade de apropriação e ressignificação desse recurso. Porém, apenas a tecnologia não garante o desenvolvimento de um pensamento artístico ou da construção do conhecimento em Arte. Pimental (2012) afirma que "conhecer o instrumento de trabalho e as possibilidades que ele oferece é essencial, mas ir além da mera aplicação dessas possibilidades é fundamental" (PIMENTEL, 2012, p. 117). A pesquisadora ainda pondera que o uso das TIC é determinante para um ensino mais crítico, por meio da vinculação de informações conectadas ao contexto no qual se inserem, atentando para a ampliação das possibilidades de produção em arte de forma inclusiva, com intermédio das tecnologias assistivas.

Entende-se, desse modo, que o docente habilitado a ministrar o componente curricular Arte necessita de conhecimentos teóricos e práticos para que os objetivos do processo de ensino e aprendizagem sejam alcançados de forma satisfatória. Isto é, conhecimentos que abrangem estética, história da arte, crítica e sociologia da arte, aliados a conhecimentos de produção artística, técnicas de expressão artísticas e conhecimentos pedagógicos. Logo, as instituições de formação inicial desses profissionais são determinantes na preparação dos futuros docentes com relação às perspectivas de uma educação no século XXI.

Existem dispositivos legais como as Diretrizes Curriculares Nacionais (DCN) para os Cursos de Graduação que orientam sobre quais os saberes necessários para o exercício profissional em uma determinada área, determinando as "[...] competências e habilidades, os componentes curriculares, o trabalho de curso, o projeto de iniciação científica, o estágio curricular supervisionado, as atividades complementares, o sistema de avaliação, além do regime acadêmico de oferta [...]" (BRASIL, 2009, p. 1).

Para a formação em artes visuais, as DCN apontam que os cursos de graduação devem estar atentos "às tecnologias de produção e reprodução visual, de novas demandas de mercado e de sua contextualização marcada pela competição e pela excelência nas diferentes modalidades de formação profissional [...]" (BRASIL, 2009, p. 4). Compreendese, portanto, que o documento apresenta apenas recomendações para o uso das tecnologias tanto como meios de ensino e aprendizagem, quanto como formas de produção artística, não existindo uma lei instituindo a obrigatoriedade de uma disciplina que trate sobre essa temática nos cursos de licenciatura ou que estabeleça o seu uso obrigatório na 
prática pedagógica docente. Diante disso, a análise curricular poderá nos ajudar a entender como se dá tal abordagem no curso de Licenciatura em Artes Visuais do IFMA.

\section{O desenho curricular do curso de Licenciatura em Artes Visuais do IFMA}

O curso de Licenciatura em Artes Visuais do Instituto Federal de Educação, Ciência e Tecnologia do Maranhão (IFMA) foi criado em 2010, com duração de quatro anos e dividido em oito semestres letivos. Sua idealização advém da enorme carência desse profissional em todos os municípios do estado do Maranhão. Outro dado para a implantação dessa licenciatura no IFMA seria a pouca oferta no estado de cursos presenciais na área, o que contribui para a permanência deste quadro de carência de professores habilitados na linguagem artística das Artes Visuais (IFMA, 2019).

O recém-criado curso do IFMA, diferente do que ainda ocorria em alguns lugares do território brasileiro, mesmo depois do projeto de lei no $7.032 / 10^{4}$ que prevê a separação das quatro linguagens artísticas (música, dança, teatro e artes visuais) na educação básica, não possuía mais característica polivalente, ou seja, formava professores(as) que, em teoria, deveriam ministrar conteúdos teóricos e práticos concentrados nas artes visuais.

Em seus dez anos de existência, o curso passou por duas alterações curriculares, a última delas ocorreu em 2019. As mudanças apresentaram variações a partir da primeira estrutura curricular, como inclusão e exclusão de disciplinas, variações dos nomes de disciplinas, inclusão ou exclusão de pré-requisitos, aumento ou diminuição de carga horária de disciplinas e do curso, revisão de ementas e bibliografias, inserção ou exclusão de bibliografia, entre outros. A descrição detalhada dessas alterações não é objeto de tal estudo, mas a título de compreensão das mudanças ocorridas, descreveremos a organização do primeiro desenho curricular (Quadro 1) e o desenho curricular de 2019 (Quadro 2).

10 período - Artes Gráficas 45h; Cultura Popular e Produção de Imagens 45h, Metodologia da Pesquisa Científica 45h, Fundamentos do Desenho 45h, História das Artes Visuais: da pré-história a Arte Neoclássica 60h;

$2^{\circ}$ período - Antropologia da Imagem 45h, Cultura de Massa e Indústria Cultural 45h, História das Artes Visuais: do Romantismo à Arte Contemporânea 60h,

\footnotetext{
${ }^{4}$ Para Alvarenga (2013), a ideia principal do Projeto de Lei no 7.032/10, é de que as linguagens artísticas específicas sejam ensinadas na educação básica separadamente, a saber, Teatro, Música, Dança e Artes Visuais; (2) sugere-se que essas linguagens sejam aplicadas, preferencialmente, quando as escolas incorporarem o ensino em período integral, e a sugestão é que as disciplinas de artes sejam no contra turno; e (3) assim que a lei for aprovada em definitivo, as escolas terão cinco anos para se adequar.
} 
Sociologia da educação 60h, Técnicas de Criatividade 45h, Tecnologia da Imagem na Modernidade 45h;

30 período - Arte da Aplicação de Materiais 30h, Didática: As Abordagens na Educação Infantil e Ensino Fundamental, Fundamentos da Fotografia 45h, Fundamentos da Pintura 45h, História das Artes Visuais III (Naturalismo a Arte Contemporânea) 60h, Pintura 60h, Linguagem Sonora 45h, Psicologia da Educação 45h, História das Artes Visuais no Brasil 45h;

$4^{\circ}$ período - Didática: Fundamentos e Metodologias para o Ensino Médio e EJA 45h, Fundamentos da Escultura 30h, Fundamentos da Gravura 45h, História e Cultura Africana e Afro-brasileira 45h, Legislação Educacional 45h, Novas Tecnologias Aplicadas à Arte 45h, Vídeo Experimental 45h;

$5^{0}$ período - Avaliação Educacional 60h, Fundamentos da Linguagem Bidimensional e Tridimensional 60h, Leitura e Produção Textual 60h, Semiologia da Imagem 60h, Filosofia e Estética da Arte 60h, História e Cultura Indígena 30h, Estágio Supervisionado: Educação Infantil 100h;

$6^{\circ}$ período - Artes Integradas $45 \mathrm{~h}$, Oficina de Cerâmica e Reciclagem 60h, Laboratório de Fotografia 45h, Metodologia do Ensino da Arte 45h, Estágio Supervisionado: Prática no Ensino Fundamental 100h, Manifestações da Arte e Cultura Africana, Afro-brasileira e Indígena 60h, Fundamentos da Educação de Jovens e Adultos 45h;

70 período - Planejamento, Elaboração de Projetos Artísticos e Organização de Exposições 60h, Estágio Supervisionado: Prática no Ensino Médio 100h, Arte e Design 45h, Currículo 60h, TCC I 30h, Libras 45h, Fundamentos da Educação a Distância 45h;

$8^{\circ}$ período - Estágio Supervisionado: Prática de Ensino Médio Técnico 100h, Arte, Memória e Patrimônio Cultural 60h, Crítica das Artes Visuais 45h, Fundamentos da Educação Especial 75h, Linguagem Corporal 75h, TCC II 45h.

Quadro 1: Desenho Curricular de 2010 Fonte: Elaborado pelo autor

A partir da análise das ementas e bibliografias dos componentes curriculares, identificou-se diferentes abordagens no que se refere às TIC e aos diferentes meios tecnológicos. A ementa da Cultura Popular e Produção de Imagens, por exemplo, traz a perspectiva dos suportes audiovisuais, incluindo o cinema, o vídeo e o computador como meios de circulação, produção e consumo da cultura popular. Enquanto o componente curricular Vídeo Experimental tem como principal objeto de estudo a linguagem do vídeo, os equipamentos e a produção videográfica, as relações entre a imagem e a máquina, a era das tecnologias do virtual.

Já o componente curricular Tecnologia da Imagem na Modernidade explora temas, como a evolução tecnológica do cinema no século XIX, o vídeo, a TV, os meios eletrônicos no mundo, a arte e as mídias, os hologramas, a informática e as tecnologias na 
contemporaneidade. Outro componente curricular, denominado Novas Tecnologias Aplicadas à Arte, propõe uma reflexão sobre a utilização de recursos tecnológicos na elaboração de proposições artísticas, e a influência dessas tecnologias na produção artística, bem como a criação de propostas artísticas com o uso de recursos computacionais.

Dentre os componentes curriculares apresentados pelo Quadro 1, a disciplina Fundamentos da Educação a Distância (EaD) aborda os conceitos de EaD, o histórico da modalidade a distância, as Tecnologias de Informação e Comunicação em EaD, ou seja, uma abordagem mais próxima dos meios tecnológicos como instrumentos de mediação pedagógica.

Após as mudanças ocorridas no desenho curricular em 2015, observa-se que as discussões sobre as tecnologias se ampliaram em oito componentes curriculares com a criação das disciplinas Arte e Tecnologia, e Tecnologias Contemporâneas na Escola. A primeira propõe reflexões sobre a utilização de recursos tecnológicos na elaboração de trabalhos artísticos, em que a tecnologia seria o meio de proposições para a produção artística. A segunda traz uma abordagem teórica que se fundamenta no uso das tecnologias contemporâneas na educação, o uso pedagógico da informática na arteeducação, programas governamentais de uso das TIC na educação.

O componente curricular Fundamentos da Fotografia introduz conceitos teóricospráticos-analíticos da fotografia e da máquina e equipamentos, enquanto o Cinema, Vídeo e Educação trabalha a evolução do cinema e introduz estudos da TV e do vídeo como processo de comunicação visual em suas dimensões educativas. As Linguagens Fotográficas, por sua vez, têm como foco a produção de ensaios e mostras coletivas, desenvolvimento de estudos aplicados e considerações estéticas acerca das intencionalidades e significações da linguagem fotográfica.

A Linguagem Sonora tem no ementário a produção de áudio-reflexões sobre o som em audiovisuais e derivados, aplicação e prática em audiovisual: manuseio e utilização de equipamentos. A ementa de Linguagem e Narrativa Cinematográfica explora a câmera e seu papel criador, poéticas e produção de narrativas fílmicas, concepção, captação e montagem cinematográfica. Por fim, a Arte e Cultura Popular propõe relações entre a literatura oral, a música, o corpo e as dimensões visuais do popular, ou seja, a análise e a criação de produtos e narrativas gerados em suportes audiovisuais (cinema, vídeo, fotografia) sobre a cultura popular. 
$\mathrm{Na}$ última reestruturação da matriz curricular do curso, os componentes curriculares estão apresentados de forma a explorar os conteúdos interdisciplinarmente, transitando entre a formação profissional e a formação pedagógica. Mas, para efeito de concepção curricular, os componentes curriculares serão apresentados por período com as respectivas cargas horárias, conforme o quadro a seguir:

10 período - Fundamentos da linguagem bidimensional e tridimensional 60h, História das Artes Visuais I 60h, Leitura e Produção de Texto 45h, Metodologia da Pesquisa Científica 45h, Fundamentos da Fotografia 45h, Fundamentos da Arte Educação 60h, Fundamentos Históricos e Filosóficos da Educação 60h, Seminários de Práticas Interdisciplinares I 100h;

$2^{\circ}$ período - História das Artes Visuais II 60h, Desenho I 60h, Sociologia da Educação 60h, Filosofia da Arte 45h, História e Cultura Africana e Afro-brasileira 45h, Antropologia Cultural 60h, Cerâmica 60h, Seminários de Práticas Interdisciplinares II $100 \mathrm{~h}$;

30 período - História das Artes Visuais III 60h, Pintura 60h, Fundamentos Didáticos I 60h, Psicologia da Educação I 60h, Leitura de Imagem 45h, Desenho II $60 \mathrm{~h}$, Linguagens Fotográficas $60 \mathrm{~h}$, Seminários de Práticas Interdisciplinares III 100h;

$4^{\circ}$ período - Metodologias do Ensino das Artes Visuais 60h, Escultura 60h, Estudos da Performance 60h, Psicologia da Educação II 45h, Fundamentos Didáticos II 60h, Arte e Design 60h, Seminários de Práticas Interdisciplinares IV 100h, Tecnologias Contemporâneas na escola $60 \mathrm{~h}$;

$5^{\circ}$ período - História das Artes Visuais no Brasil I 60h, Política Políticas Educacionais 60h, Cultura Visual 60h, Aplicação de Materiais em artes visuais 60h, Teorias das Artes Visuais 45h, Artes Visuais no Maranhão 45h, História e Cultura Indígena 45h, Estágio Supervisionado I: Educação Infantil 100h;

$6^{\circ}$ período - Cinema, Vídeo e Educação 60h, Linguagem Sonora 60h, Gravura 60h, Estágio Supervisionado II: Ensino Fundamental 100h, Gestão escolar 60h, História das Artes visuais no Brasil II 60h, Educação Inclusiva 75h;

70 período - Pesquisa em Arte 60h, Arte, Memória e Patrimônio 60h, Poéticas contemporâneas 60h, Estágio supervisionado: Ensino Médio 150h, Linguagem e Narrativa Cinematográfica 60h, Linguagens Artísticas Integradas 60h

$8^{\circ}$ período - Ação Educativa em Espaços Culturais 60h, Crítica das Artes Visuais $60 \mathrm{~h}$, TCC 45h, Língua Brasileira de Sinais (LIBRAS) 60h.

Quadro 2: Desenho Curricular de 2019

Fonte: Elaborado pelo autor do estudo

A partir dessa recente reelaboração da matriz curricular, percebe-se que houve a manutenção da disciplina Tecnologias Contemporâneas na Escola, com apenas uma ampliação do ementário e a inclusão de bibliografias complementares. A disciplina Arte e Tecnologia foi substituída pela disciplina Poéticas Contemporâneas, apresentando uma 
abordagem semelhante à sua antecessora, com a adição de temas, como hibridismo e cibercultura e processos colaborativos na criação artística.

As análises realizadas com base nas três versões dos projetos pedagógicos do Curso de Licenciatura em Artes Visuais do IFMA permitiram constatar que há uma preocupação em contextualizar a importância do profissional em artes visuais diante de um mundo repleto de imagens, que se fazem presentes diariamente na vida do ser humano contemporâneo, nos diversos meios tecnológicos, sendo este profissional o responsável em mediar as relações humanas com a diversidade imagética.

O Quadro 3 apresenta os componentes curriculares que abordam as TIC em cada projeto. Observa-se que há uma quantidade de cinco componentes que exploram a temática no primeiro projeto do curso; em 2015, oito exploram a temática; já no projeto de 2019, as discussões se concentram em sete componentes curriculares.

\begin{tabular}{|l|l|}
\hline $\begin{array}{l}\text { Componentes curriculares } \\
\text { com abordagem das TIC } \\
\text { no projeto pedagógico de } \\
\mathbf{2 0 1 0}\end{array}$ & $\begin{array}{l}\text { Tecnologia da Imagem na Modernidade 45h } \\
\text { Cultura Popular e Produção de Imagens 45h } \\
\text { Novas Tecnologias Aplicadas à Arte 45h } \\
\text { Vídeo Experimental 45h } \\
\text { Fundamentos da Educação a Distância (EaD) } \\
45 \mathrm{~h}\end{array}$ \\
\hline $\begin{array}{l}\text { Componentes curriculares } \\
\text { com abordagem as TIC no } \\
\text { projeto pedagógico 2015 }\end{array}$ & $\begin{array}{l}\text { Tecnologias Contemporâneas na Escola 60h } \\
\text { Fundamentos da Fotografia 45h } \\
\text { Cinema, Vídeo e Educação 60h } \\
\text { Linguagem Sonora 60h } \\
\text { Arte e Cultura Popular 45h } \\
\text { Linguagens Fotográficas 60h } \\
\text { Linguagem e Narrativa Cinematográfica 60h }\end{array}$ \\
\hline $\begin{array}{l}\text { Componentes curriculares } \\
\text { com abordagem das TIC } \\
\text { no projeto pedagógico } \\
\mathbf{2 0 1 9}\end{array}$ & $\begin{array}{l}\text { Tecnologias Contemporâneas na Escola 60h } \\
\text { Poéticas Contemporâneas 60h } \\
\text { Fundamentos da Fotografia 45h } \\
\text { Cinema, Vídeo e Educação 60h } \\
\text { Linguagem Sonora 60h } \\
\text { Linguagens Fotográficas 60h } \\
\text { Linguagem e Narrativa Cinematográfica 60h }\end{array}$ \\
\hline
\end{tabular}

Quadro 3: Componentes Curriculares que abordam as tecnologias em cada projeto pedagógico

Fonte: Elaborado pelo autor

Nos projetos pedagógicos analisados por esse estudo foram citadas as mudanças promovidas perante as revoluções tecnológicas, ocorridas a partir do século XIX, que possibilitaram o surgimento de linguagens artísticas, como a fotografia, o cinema, a televisão, o vídeo, a internet etc., e que influenciam a atual produção de imagens. Além 
disso, identificaram-se diferentes abordagens das TIC, em disciplinas mais voltadas em explorar conhecimentos teóricos e práticos, relacionadas à arte e a seu contato com os recursos tecnológicos e outras abordagens que se aproximam mais do uso das tecnologias como meios de mediação pedagógica. Nesse sentido, pode-se perceber que a instituição de ensino, representada pelo corpo docente do Curso de Licenciatura em Artes Visuais do IFMA, responsáveis pela criação e atualizações dos projetos, está atenta às mudanças na sociedade contemporânea, na Arte e na educação dos dias atuais.

De acordo o próprio texto das DCN de Artes Visuais, um dos seus papéis do documento é orientar a organização dos cursos, expressa no Plano Político Pedagógico (PPP), o qual determina o perfil do formando sobre "[...] as competências e habilidades, os componentes curriculares, o trabalho de curso, o projeto de iniciação científica, o estágio curricular supervisionado, as atividades complementares, o sistema de avaliação, além do regime acadêmico de oferta [...]" (BRASIL, 2009, p. 1). Nesse sentido, as leis e documentos balizadores ressaltam a importância de se abordar determinados conteúdos e temáticas na matriz curricular de um Curso de Licenciatura em Artes Visuais, o qual precisa envolver questões de contexto amplo, decorrentes tanto das demandas por qualificação da educação básica quanto do que é contemporaneamente discutido no campo da Arte, ao mesmo tempo ficando a cargo das instituições de ensino superior a responsabilidade de inserirem, nos projetos de cursos, questões de acordo com as atuais demandas educacionais.

\section{Considerações finais}

As Tecnologias de Informação e Comunicação (TIC) estão sendo apropriadas pela educação com o objetivo de aprimorar o processo de ensino e aprendizagem, como uma das tendências pós-moderna de uma sociedade mediada por diferentes aparatos tecnológicos. Diante de tal fato, é impossível continuar oferecendo o mesmo tipo de educação de anos atrás. O professor deixa de ocupar o papel de detentor do saber, de transmissor dos conteúdos em aulas tradicionais, e agora tem o desafio de ser mediador das relações entre o conhecimento, os alunos e as tecnologias.

Nesse sentido, a preparação e a qualificação do profissional que atuará no ensino de Arte, objeto principal deste estudo, devem estar pautadas em conhecimentos abrangendo a estética, a história da arte, crítica e sociologia da arte, aliados a conhecimentos de produção artística, técnicas de expressão artísticas e conhecimentos pedagógicos. Além disso, precisam também aprender a explorar os artefatos tecnológicos 
como meios de expressão artística e como instrumentos facilitadores do processo de ensino e aprendizagem, com um enorme interesse em fazer arte e ensinar outros a fazer arte. Desse modo, devem possibilitar o acesso do alunado a essas diversas produções artísticas, apropriando-se de várias metodologias e inovações nos procedimentos educativos.

Além da existência das DCN que orientam os cursos de Graduação em Artes Visuais, a BNCC apresenta recomendações na prática profissional dos professores de Arte na educação básica, bem como habilidades e competências que deverão ser desenvolvidas a partir do uso de tecnologias no contexto escolar. O próprio projeto pedagógico do Curso de Licenciatura em Artes Visuais do IFMA indica direcionamento sobre qual perfil profissional pretende formar, e quais as competências profissionais são necessárias para o exercício profissional na contemporaneidade.

A partir dos dados analisados, conclui-se que as abordagens das tecnologias se apresentam em diferentes formas na estrutura curricular do Curso de Licenciatura em Artes Visuais. Em disciplinas, a exemplo de Poéticas Contemporâneas, os recursos tecnológicos são abordados como instrumentos e meios de produção artística, enquanto que, em disciplinas como Tecnologias Contemporâneas na Escola, são exploradas como ferramentas de mediação pedagógica.

Diante disso, pode-se inferir que a abordagem de tal temática no projeto pedagógico do curso de formação docente não garantirá que os seus alunos (futuros professores) saberão aplicar os conhecimentos adquiridos durante o curso em suas práticas profissionais. É preciso que essas discussões não se limitem a duas ou três disciplinas na estrutura curricular, sendo necessária sua ampliação e integração para todos os componentes curriculares e que seja trabalhada de forma inovadora durante a graduação. Assim, os(as) docentes do Curso assumem um papel de relevância nesse processo, porque podem ser exemplos práticos ao explorarem as potencialidades pedagógicas dessas tecnologias e ao adotarem novas metodologias de ensino e aprendizagem, inspirando as futuras práticas dos seus alunos (futuros docentes).

Vê-se, portanto, que há a necessidade de se tematizar as TIC nos Cursos de Licenciaturas em Artes Visuais de forma criativa e inovadora, para que o(a) licenciado(a) em Artes Visuais possa se sentir mais seguro a utilizar as tecnologias de forma crítica e reflexiva com intuito de auxiliá-lo em sua prática docente diante dos constantes desafios e emergentes mudanças que a educação do século XXI Ihe impõe. 


\section{Referências}

ALVARENGA, V. M. O projeto de Lei no 7.032/10 prevê linguagens artísticas separadas na Educação Básica: será o fim da polivalência? Linguagens - Revista de Letras, Artes e Comunicação. Blumenau, v. 7, n. 3, p. 261-275, set/dez. 2013. Disponível em: <https://proxy.furb.br/ojs/index.php/linguagens/article/view/4067/2593>. Acesso em: 3 jan. 2020.

BRASIL, MEC. Conselho Nacional de Educação/ Câmara de Educação Superior. Parecer homologado: Diretrizes Curriculares Nacionais do Curso de Graduação em Artes Visuais, bacharelado e licenciatura. Distrito Federal. 2009. Disponível em: <http://portal.mec.gov.br/cne/arquivos/pdf/2007/pces280_07.pdf>. Acesso em: 18 abr. 2020.

BRASIL, MEC. Base Nacional Comum Curricular. 2017. Disponível em: <http://basenacionalcomum.mec.gov.br/>. Acesso em: 27 mai. 2020.

CASTELLS, M. A sociedade em rede. Tradução de Roneilde Venâncio Majer. 17. ed. revista e ampliada. São Paulo: Paz e Terra, 2016.

GATTI, B. A.; BARRETO, E. S. Professores: aspectos de sua profissionalização, formação e valorização social. Brasília, DF: UNESCO, 2009.

IMBERNÓN, Francisco. Formação docente e profissional: formar-se para a mudança e a incerteza. 2. ed. São Paulo: Cortez, 2001.

IMBERNÓN, Francisco. Formação docente e profissional: formar-se para a mudança e a incerteza. São Paulo: Cortez, 2006.

INSTITUTO FEDERAL DE EDUCAÇÃO CIÊNCIA E TECNOLOGIA DO MARANHÃO. Projeto Pedagógico da Licenciatura em Artes Visuais. São Luís, 2019. Disponível em:< https://drive.google.com/file/d/10p1ujpKIZ8uItfxKMWzy2RSiuPNVF0y8/view>. Acesso em: 17 abr. 2020.

KANDINSKY, W. Do espiritual da arte. Tradução de Álvaro Cabral e Antônio de Pádua Danesi. São Paulo: Martins Fontes, 1996.

KENSKI, V. M. Tecnologia Educacional: uma nova cultura de ensino e aprendizagem na universidade. SPELLER, P. ROHL, F., MENEGHEL, S. M. (Org.). UNESCO. Desafios e Perspectivas da Educação Superior Brasileira para a Próxima Década (2011-2020). Brasília: UNESCO, CNE, MEC, 2012. 164p. Disponível em:< http://www.unesco.org/new/pt/brasilia>. Acesso: 08 jun. 2020.

LÉVY, Pierre. Cibercultura. Tradução de Carlos Irineu da Costa. São Paulo: ed. 34, 1993.

MACHADO, A. Arte e mídia: aproximações e distinções. Galáxia: Revista transdisciplinar de comunicação, semiótica, cultura. São Paulo, n. 4, p. 19-32, 2002. Disponível em: <http://revistas.pucsp.br/index.php/galaxia/article/view/1289>. Acesso em: 21 dez. 2020.

PERRENOUD, Philippe. Dez novas competências para ensinar. Porto Alegre: Artmed, 2000. 
PIMENTEL, L. G. Tecnologias contemporâneas e o ensino da Arte. In: Inquietações e mudanças no ensino da arte. Organizado por Ana Mae Barbosa. 7. ed. São Paulo: Cortez, 2012.

PIMENTEL, L. G. Novas territorialidades e identidades culturais: o ensino de arte e as tecnologias contemporâneas. Anais da ANPAP, pp. 765-771. Disponível em: <http://www.anpap.org.br/anais/2011/pdf/ceav/lucia_gouvea_pimentel.pdf >. Acesso em: 13 abr. 2020.

PÚBLIO JÚNIOR, Claudemir. O docente e o uso das tecnologias no processo de ensinar e aprender. Revista Ibero-Americana de Estudos em Educação, Araraquara, v. 13, n. 03, p. 1092-1105. Disponível em: <https://periodicos.fclar.unesp.br/iberoamericana/article/view/11190/7521>. Acesso em: 17 dez. 2019.

UNESCO. Padrões de competência em TIC para professores - diretrizes de implementação. Organização das Nações Unidas para a Educação, a Ciência e Cultura (UNESCO). 2009. Disponível em: <http://unesdoc.unesco.org/images/0015/001562/156209por.pdf>. Acesso em: 06 abr. 2020.

\footnotetext{
' Mestrando em Engenharia e Gestão do Conhecimento (UFSC) na linha de pesquisa Mídia do Conhecimento. Especialista em Arte, Mídia e Educação e licenciado em Artes Visuais pelo Instituto Federal de Educação, Ciência e Tecnologia do Maranhão (IFMA). É tecnólogo em Marketing pelo Centro Universitário Internacional (UNINTER). Participa do Grupo de Estudos e Pesquisa Interdisciplinar em Arte e Educação (GEPIARTE)/UFMA/CNPq e do Grupo de Pesquisa em Tecnologia, Arte e Educação (GPTAE). Tem interesse nas temáticas: ensino de arte, formação de professores, educação a distância e tecnologias aplicadas à arte.

ii Possui graduação em Bacharelado em Comunicação Social pela Universidade Federal do Maranhão (2003). Graduação em Licenciatura em Educação Artística pela Universidade Federal do Maranhão (2000). Mestrado em Cultura e Sociedade pela Universidade Federal do Maranhão. Doutorado em Informática na Educação pela Universidade Federal do Rio Grande do Sul. Atualmente é professora do Instituto Federal do Maranhão nos cursos técnicos e na graduação. Coordena o Grupo de Pesquisa em Tecnologia, Arte e Educação (GPTAE). Tem experiência como docente e como pesquisadora na área de Arte, com ênfase em Artes Visuais, atuando principalmente nos seguintes temas: ensino de arte, formação de professores, educação a distância e tecnologias aplicadas a arte.
}

Como citar esse artigo:

COSTA, William Cordeiro; BARROS, Luciana Silva Aguiar Mendes. As TIC no desenho curricular do Curso de Licenciatura em Artes Visuais do IFMA. Revista Digital do LAV, Santa Maria: UFSM, v. 14, n. 1, p. 159-176, jan./abr. 2021. 